\title{
ENERGY EFFICIENT NETWORK MANUFACTURING SYSTEM USING CONTROLLED ELITIST NON-DOMINATED SORTING GENETIC ALGORITHM
}

\author{
Veera Babu Ramakurthi' ${ }^{1}$ V. K. Manupati ${ }^{1}$, Leonilde Varela ${ }^{2}$, José Machado ${ }^{3}$ \\ ${ }^{1}$ Department of Mechanical Engineering, National Institute of Technology Warangal, India \\ ${ }^{2}$ Algoritmi Research Centre, University of Minho, Portugal \\ ${ }^{3}$ MEtRICs Research Centre, University of Minho, Portugal \\ Emails: rvbabu.nitw@gmail.com; manupati.vijay@nitw.ac.in, leonilde@dps.uminho.pt, \\ jmachado@dem.uminho.pt
}

\begin{abstract}
Recent manufacturing systems did not just confine to optimal utilization of resources due to the global stance on strict environmental regimes. Collaborative effort to achieve sustainable practices in the decentralized manufacturing environment is a new complex problem. In this paper, with a networked manufacturing system we try to achieve both traditional as well as sustainable parameters by optimizing the performances such as makespan, machine utilization, and energy consumption. Thereafter, we formulate the problem as a mixed-integer non-linear programming (MINLP) model. To handle this NP-hard problem and to find the optimal solutions a Controlled elitist non-dominated sorting genetic algorithm (CE-NSGA-II) has been adopted. Finally, the results are analyzed with different scenarios to prove the proposed approach validation.
\end{abstract}

Keywords: Networked Manufacturing System, Sustainability, Genetic Algorithm, Optimization.

\section{Introduction}

Since most resources are non-renewable, globalization and rapid development in developing countries have led to increased consumption in energy resources. The industrial manufacturing sectors are consuming almost half of the energy delivered by the world according to Environmental Impact Assessment (EIA). In addition, countries like China, India, and Brazil, there is a global demand for a large variety of goods due to their relatively higher population growth and development in overall living standards. However, to fulfill their needs, the resources required are quite scarce. Hence, the efficient and sustainable utilization of resources has to be adopted, especially in the manufacturing sector (Haapala et al., 2013). Sustainable development has been defined as development to satisfy the needs of the present without affecting the ability of future generations to meet their own needs by taking into account economic, social, and environmental dimensions (Jovane et al., 2008).

In addition, markets should sustain the benefits of enormous market competition owing to the fact that increased intricacy and functionality of vastly demanded products. The overall economic contest has certain advantages such as reduced cycle-time in the manufacturing system, ultimate data information, the standard flow of knowledge, etc.
Inorder to achieve the mentioned requirements, current conventional manufacturing scenarios have to be renovated so that globally growing customer's demand can be satisfied. In this study, a Networked manufacturing (NM) environment has considered to gain the advantage that lacks in the conventional manufacturing system. In this research, a multiobjective network-based manufacturing model of customers, enterprise users, and a cloud of enterprises are developed to optimize makespan, machine utilization, and energy consumption while disclosing a product.

Several new-generation manufacturing systems emerged in recent times which can capable enough to adopt to changes in environmental market conditions, especially when numerous turbulent variations are evolved in the market demand (Peklenik and Jerele, 1992). However, an enterprise can attain improved quality and cost-efficient manufacturing schedule by boosting the manufacturing system's reconfigurability and flexibility through introducing a distributed paradigm (Veeramani, 1997; Wilde and Briscoe, 2011). These specified needs and their functionalities can be upheld by applying networked manufacturing approach. The definition, functions, advantages, application and its limitations are detailed in different studies (Varela et al., 2019). 
Networked manufacturing situations quite different from the monolithic approach in job scheduling criterion. Hence, the idea of a conventional job scheduling concept is expanded and reorganized. In networked-based manufacturing, various jobs consist of competition issues in between them so individual optimal results are generated which is different from the traditional case of manufacturing. However, the characteristics of realworld production atmosphere are stochastic and this system is perfectly distinguished by taking many optimizing objective functions concurrently. As a result, efficient algorithms are necessary for a widerange thus optimal solutions can be achieved in lesser computational run time.

Ausaf et al. (2015) presented a priority-based optimization algorithm (PBOA) that utilizes a mixture of operation engagement prioritization along with a structure of dispatching rules to help in efficiently generating a schedule for MOIPPS. Considering the intricacies of practical IPP (Integrated Production Planning) like wide-reaching decision variables, several objective functions, and uncertainty in interval-valued parameters. Lin et al. (2016) introduced a novel "order-set" concept to be used with modified interval-MOEA pertaining to steel-making continuous casting-hot rolling process and it was implemented in an iron-steel company of China after testing with their routine production data. Luo et al., (2017) proposed a multi-objective genetic algorithm (MOGA) based on the immune principle associated with density mechanism and external archive to establish a much better IPPS with maintained diversification of population, avoided premature condition and sustained Pareto fronts. Zhao et al., (2018) discussed a job shop scheduling problem with unrelated parallel machines, and a two-generation Pareto ant colony multi-objective algorithm has been formed that splits the problem into two sub-problems with inheritance relationship and the optimization criteria in two phases.

Problem description containing suitable assumptions, mathematical models, and constraints are developed in Section 2. Controlled elitist nondominated sorting genetic algorithm (CE-NSGA-II) Framework is discussed in Section 3. Section 4 consists of a demonstrative example for three cases. The results obtained are discussed in Section 5. Section 6 includes the conclusion of the paper and discussion on the scope for future opportunities.

\section{Problem Description}

A problem of the distributed network-based manufacturing system is considered, which is having a set of $n$ jobs $\left\{J_{1}, \ldots, J_{n}\right\}$ of orders accepted from various customers, and $m$ available machines $\left\{R_{1}, \ldots\right.$, $\left.R_{m}\right\}$. A particular set of schemes or substitute process plans are associated with each job $J_{i}$ and a series of sequential $V_{i}$ operations $\left(O_{i l}, \ldots, O_{i v i}\right)$ is linked to each process plan. Consequently, the available machines are employed to process jobs with different possible process plans at different enterprises to achieve better use of resources and satisfactory delivery schedules. Each machine can be operated with different speeds due to their dispersion over geographically distributed enterprises, thus each task is associated with an integer energy Eoil and duration $P_{\text {oil }}$ used by the corresponding machine.

The association between duration and energy can be expressed as "Job(Speed) II Makespan, Energy" for this problem. Each task is operated with altered speeds and each speed results in a specific processing time and energy consumption. The operation time decreases with the increase in working speed which also results in increased energy consumption. In this paper, different jobs, their predecessor and successor operations, machine candidates, processing time, energy efficiency have been considered.

The objective is to determine the best suitable enterprise and feasible schedule which combines minimization of the makespan and the energy consumed by the machines with maximized resource utilization. Hence, the dead time can be retrieved by escalating the machine's speed if a task is delayed to recover the original solution. The mentioned network-based manufacturing case is one of the intricate problems of the current scenario where a vital role is played by the servicing operating time and transporting time between two corresponding machines to sustain process planning and scheduling functions.

Being a large research space, the problem becomes intricate for resulting out the best suiting optimal solution. Therefore, IPPS provides the prospective to produce an effectual optimized process plan due to flexibility in networked manufacturing. Hence, the origination of optimal process plans related to every job linked with constraints becomes a demanding task so; it can be taken as a new problem on the report of current manufacturing circumstances.

\subsection{Assumptions}

1. Job pre-emption is not permitted.

2. Any task of a job being operated on any available machine should be completed without any interruption until it finishes.

3. Only one job is to be handled by each machine at a point time.

4. All jobs and machines can go under process ontime zero.

5. A linear relation between energy consumption and speed is considered.

6. A linear relation between energy consumption and speed is considered. 


\subsection{Decision Variables}

$$
\begin{aligned}
& \alpha_{j p}=\left\{\begin{array}{l}
1 ; \text { if the } p^{\text {th }} \text { flexible process plan of } j^{\text {th }} \text { job is selected } \\
0 ; \text { otherwise }
\end{array}\right. \\
& \beta_{j p o Q r s m}=\left\{\begin{array}{l}
1 ; \text { the operation } U_{j p o} \text { precedes the operation } O_{Q r s} \text { on machine } \mathrm{m} \\
0 ; \text { otherwise }
\end{array}\right. \\
& \gamma_{j p o m}=\left\{\begin{array}{l}
1 ; \text { if machine } m \text { is selected for } O_{j p o} \\
0 ; \text { otherwise }
\end{array}\right. \\
& A_{j p o m}=\left\{\begin{array}{l}
1, \text { if the operation } O_{j p o} \text { is being processed on } m^{t h} \text { machine } \\
0, \text { otherwise }
\end{array}\right. \\
& \begin{array}{c}
G_{j p o q r k m}= \begin{cases}1 & \text { if operation } O_{j p o} \text { is the successor of operation } O_{q r k} \text { on } m^{\text {th }} \text { machine } \\
0 & \text { if operation } O_{j p o} \text { and operation } O_{q r k} \text { are not adjacent } \\
-1 & \text { if operation } O_{j p o} \text { is preceding operation } O_{q r k}\end{cases} \\
D_{j p o m}=\left\{\begin{array}{l}
1, \text { if } m^{\text {th }} \text { machine is to be turned off between the operation } O_{j p o} \text { and operation } O_{q r k} \\
0, \text { if } m^{\text {th }} \text { machine to be turned on between the operation } O_{j p o} \text { and operation } O_{q r k}
\end{array}\right.
\end{array}
\end{aligned}
$$

\subsection{Mathematical Modelling}

The desired outcomes of this problem are minimization of makespan, maximization of machine utilization, and minimization of energy consumption as represented as follows:

\section{Objectives:}

Makespan minimisation:

$$
T_{j}=\operatorname{Max} C_{j p o m}
$$

Maximization of machine utilization:

$$
m u=\frac{\sum_{s=1}^{m} m p t_{s}}{\sum_{s=1}^{m}\left(m c t_{s}-m s t_{s}\right)}
$$

Minimization of energy consumption:

$$
\varnothing=\sum_{m=1}^{S}\left(\varnothing_{0 / 1 m}+\varnothing_{i m}+\varnothing_{p m}+\varnothing_{s m}\right)
$$

\subsubsection{The energy consumption model}

It can be divided into four operating states as follows.

\section{a. The turning on/off state}

$\emptyset_{0 / 1 m}=z_{m}\left[\int_{F_{m}}^{F_{m}+D_{m 1}} \mu_{m}(t) d t+\int_{G_{m}-D_{m 2}}^{G_{m}} \mu_{m}(t) d t\right] \max _{j, o}\left(X_{i j k q}\right)$

$$
F_{m}=\min _{j, o}\left(A_{j p o m}\left(E_{j p o m}-P t_{j p o m}\right)\right)
$$

$G_{m}=\max _{j, o}\left(A_{j p o m} E_{j p o m}\right)$

\section{b. The idle state}

$\boldsymbol{\emptyset}_{i m}=\sum_{j, q}^{N} \sum_{o, k}^{\max \left(V_{j p}, V_{q r}\right)} \boldsymbol{\emptyset}_{\text {im jpoqrk }}$

$$
\emptyset_{\text {imjpoqrk }}=\left\{\begin{array}{l}
Q\left(Q_{1}\left(\max \left(F_{m 1}+L_{m}, E_{j p o m}\right)-E_{j p o m}\right)+\left(Q_{2}\left(\max \left(F_{m_{1}}+L_{m}, E_{q r k m}\right)-E_{q r k m}\right), D_{j p o q r k}=1\right.\right. \\
Q\left(Q_{1}\left(E_{q r k m}-P t_{q r k m}-E_{j p o m}\right)+Q_{2}\left(E_{j p o m}-P t_{j p o m}-E_{q r k m}\right)\right), D_{j p o q r k}=0
\end{array}\right.
$$

\section{c. The processing state}

$\varnothing_{p m}=W_{m}\left(\sum_{j}^{N} \sum_{o}^{V_{j p}} A_{j p o m} P t_{j p o m}\right)$

\section{d. The standby state}

$$
\emptyset_{s m}=C_{\max } Y_{s m}
$$




\section{Constraints:}

For the initial operation in the $p^{\text {th }}$ process plan for $j^{\text {th }}$ job:

$$
C_{j p 1 m}+\theta\left(1-\alpha_{j p}\right) \geq P t_{j p 1 m}
$$

For the final operation in the $p^{\text {th }}$ process plan for $j^{\text {th }}$ job:

$$
C_{j v_{j p} j p}-\theta\left(1-\alpha_{j p}\right) \leq C_{j p o m}
$$

A job's different operations cannot be processed simultaneously.

$C_{j p o m}-C_{j p(o-1) m}+\theta\left(1-\alpha_{j p}\right) \geq P t_{j p o m}$

Only one job is to be handled by each machine at a point of time

$$
C_{\text {jpom }}-C_{Q r s m}+\theta \beta_{\text {jpoQrsm }} \geq P t_{\text {jpom }}
$$
plan

Each job can be associated with single process

$$
\sum_{p=1}^{P_{j}} \alpha_{j p}=1
$$

Each operation can be process on a single machine only

$$
\begin{aligned}
& \sum_{m=1}^{S} \gamma_{j p o m}=1 \\
& E_{j p o}-P t_{j p o} \geq E_{j p(o-1)}
\end{aligned}
$$

$$
\left(G_{j p o q k m} / 2\right)\left(G_{j p o q k m}-1\right)\left(E_{q r k}-E_{j p o}-P t_{q r k m}\right) A_{j p o m} A_{q r k m}+\left(G_{j p o q r k m} / 2\right)\left(G_{j p o q r k m}+1\right)\left(E_{j p o}-E_{q r k}-P t_{j p o m}\right) A_{j p o m} A_{q r k m} \geq 0
$$

$$
\begin{aligned}
& \sum_{m=1}^{S} A_{\text {jpom }}=1 \\
& E_{j p o m} \geq 0 \\
& P t_{j p o m} \geq 0
\end{aligned}
$$

This problem's objectives are to primarily emphasize on job scheduling so that maximum of their total completion time of all operations can be minimized, i.e., makespan as specified in Equation (1); maximization of the machine or resource utilization as referred in Equation (2); and to minimize the Energy consumption of machines as specified in energy consumption framework. The problem is subjected to certain constraints which are listed in the equations (13)-(25). Constraint (13) expresses restriction in processing various operations related to a job concurrently for alternative process plans. Constraint (14) states that only a single operation can be operated on any machine at a time. Constraint (15) comprises that each job can be related to only one single process plan. Constraint (16) shows that a single machine is to be selected for each operation. The precedence relation is depicted in Equation. (19). Constraint (20) states that only one job can be processed by any machine at a point of time. Constraint (21) represents a decision variable that is used to assign availability of the machines at a particular time. Practicality of our problem is portrayed in (22) and (23).

\section{Controlled Elitist Non Dominated Sorting Genetic Algorithm (CE-NSGA-II)}

Quick erasure of non-elitist front solutions and lack of variety in some decision variables are undesired outcomes of NSGA-II, which leads to the significance of the much superior CE-NSGAII algorithm.
The following sections describe various stages of the CE-NSGA-II algorithm in the reference of networked manufacturing problems having multi-objectives and above-disclosed outcomes of NSGA-II and the parameters for the proposed algorithm is shown in Table 1.

Table 1. Parameter values for algorithm

\begin{tabular}{|l|l|}
\hline Parameter & Parameter Value \\
\hline Population Size & 50 \\
\hline Maximum Generations & 50 \\
\hline Mutation Probability $\left(\mathrm{M}_{\mathrm{p}}\right)$ & 0.05 \\
\hline Cross-over Probability $\left(\mathrm{C}_{\mathrm{p}}\right)$ & 0.84 \\
\hline
\end{tabular}

\subsection{Population Initialization}

At first, the initial population is generated arbitrarily for specified population size. The process also plays a major role in obtaining more optimal solutions. It has been proven that the initial populations generated may affect the best value of the objective function and that their effects may last for several generations (Maaranen et al., 2007).

\subsection{Evolutionary Operations}

In the process of evolution, genetic variation is necessary. The operations that are performed are analogous to those happening in nature in the process of evolution: Survival of the fittest or selection, mutation, and crossover (also called as reproduction or recombination). These operations are carried out to protect the diversity in the population $N$ and to create a new child population of the same size. The detailed flowchart of the CENSGA-II is detailed in Fig. 1. 


\section{Selection.}

In this operation, better solutions are given more preference which allows them to pass on their genes to the next generation during the execution of the algorithm. This is the preliminary step before performing cross-over or mutation.

The best solutions are selected using the fitness values of the objective functions. The fitness value represents the closeness of the solution in achieving the specified objective. There are various methods of selection used for different applications. In our case, we have used a tournament selection in the algorithm.

\section{Mutation.}

The mutation is used to develop the solution space by generating neighbors in different directions. It can be executed in four methods as swap, insertion, displacement, and inversion where the first two produce close neighbors while the other two create distant neighbors.

This operation protects the robust intermediate solutions by diversification and to adjust the fragile ones. Here bit wise mutation is employed with Pm (mutation probability) as 0.05 .

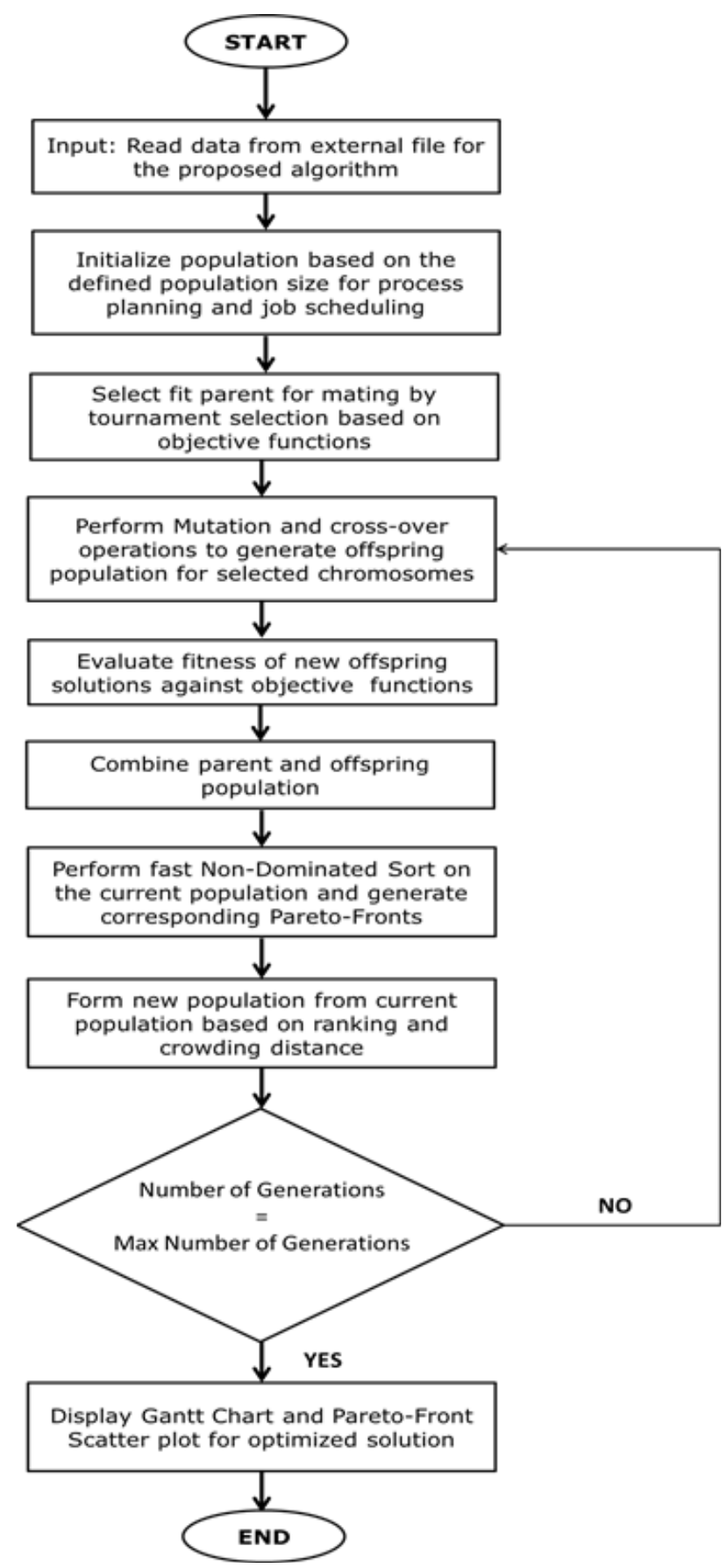

Figure 1. CE-NSGA-II Framework 


\section{Demonstrative Example}

Three illustrative instances (represented by $\mathrm{n} \times \mathrm{m}$ / Job X Machine problem) have been chosen as a testbed to represent the performance and efficacy of the proposed algorithm. Available machine and processing time data are taken (Zhou et al., 2010; Shao et al., 2009) and the energy consumption is computed through the mathematical model using practical machine power and speed parameters. CE-NSGA-II algorithm is applied to obtain optimized process planning and scheduling with minimum makespan, maximum machine utilization, and minimum energy consumption. Tables 1, 2, and 3 have the input data to the algorithm for the three cases respectively. Three different brackets are used to represent the parameter's data. Available machines, processing time, and energy consumption are placed in curly, square, and round brackets respectively. For example, $j_{3}$ job's $O_{3}$ has available machines as $\{2$, $5\}$, corresponding $[5,6]$ minutes processing time, and $(372,378)$ kilo-joule energy consumption.

\subsection{Scenario 1}

This scenario exhibits the order placed by costumers for six different jobs where the corresponding operations are to be processed by six geographically located machines at different enterprises. Anyone of multiple process plans can be employed for each job and multiple machines are available to process each operation.

Popularly applied scheduling representation means i.e., Gantt chart is characterized in Fig.2, which pictures the allotment of operations on various available machines, beginning and ending time of each operation, and the optimized process plan. Time and machines are represented on $X$ and $Y$-axis of the Gantt chart. The output results for makespan selected optimal process plan and job scheduling obtained from the algorithm are shown in Table 4.

\subsection{Scenario 2}

Case of eight different jobs from clients to be processed at eight machines available in the network manufacturing system is explored in scenario 2 . The output results for makespan selected optimal process plan and job scheduling obtained from the algorithm are shown in Table 5 . The job scheduling Gantt chart is presented in Fig. 3.

\subsection{Scenario 3}

This scenario consists of six different jobs to be completed through processing operations using eight available machines. The output results for makespan selected optimal process plan and job scheduling obtained from the algorithm are shown in Table 6 and the Gantt chart is shown in Fig. 4.

Table 2. Input data of scenario 1

\begin{tabular}{|c|c|c|c|c|c|c|c|}
\hline \multicolumn{8}{|c|}{ Input data of Scenario 1} \\
\hline & & \multicolumn{6}{|c|}{ Operations } \\
\hline Job & PP & $\mathbf{O}_{1}$ & $\mathrm{O}_{2}$ & $\mathrm{O}_{3}$ & $\mathbf{O}_{4}$ & $\mathbf{O}_{5}$ & $\mathbf{O}_{6}$ \\
\hline \multirow{6}{*}{$\mathrm{J}_{1}$} & \multirow{3}{*}{$\mathrm{PP}_{1,1}$} & $\{1,2\}$ & $\{3,4,5\}$ & $\{6\}$ & & & \\
\hline & & {$[6,5]$} & {$[7,6,6]$} & [8] & & & \\
\hline & & $(493,372)$ & $(496,410,378)$ & (619) & & & \\
\hline & \multirow{3}{*}{$\mathrm{PP}_{1,2}$} & $\{1,3\}$ & $\{2,4\}$ & $\{3,5\}$ & $\{4,5,6\}$ & & \\
\hline & & {$[4,5]$} & {$[4,5]$} & {$[5,6]$} & {$[5,5,4]$} & & \\
\hline & & $(329,354)$ & $(298,342)$ & $(354,378)$ & $(342,315,310)$ & & \\
\hline \multirow{6}{*}{$\mathrm{J}_{2}$} & \multirow{3}{*}{$\mathrm{PP}_{2,1}$} & $\{2\}$ & $\{1,3\}$ & $\{2,4,6\}$ & $\{3,5\}$ & $\{2,4\}$ & $\{4,6\}$ \\
\hline & & [4] & {$[2,3]$} & {$[4,3,5]$} & {$[2,4]$} & {$[3,4]$} & {$[3,5]$} \\
\hline & & (298) & $(164,212)$ & $(298,205,387)$ & $(142,252)$ & $(223,274)$ & $(205,387)$ \\
\hline & \multirow{3}{*}{$\mathrm{PP}_{2,2}$} & $\{1,3,5\}$ & $\{4\}$ & $\{4,6\}$ & $\{4\}$ & $\{4,6\}$ & $\{1,6\}$ \\
\hline & & {$[1,5,7]$} & [5] & {$[1,6]$} & {$[4]$} & {$[1,2]$} & {$[5,6]$} \\
\hline & & $(82,354,441)$ & $(342)$ & $(68,464)$ & $(274)$ & $(68,155)$ & $(411,464)$ \\
\hline \multirow{8}{*}{$\mathrm{J}_{3}$} & \multirow{3}{*}{$\mathrm{PP}_{3,1}$} & $\{2,3\}$ & $\{1,4\}$ & $\{2,5\}$ & $\{3,6\}$ & $\{1,6\}$ & $\{5\}$ \\
\hline & & {$[5,6]$} & {$[6,5]$} & {$[5,6]$} & {$[6,5]$} & {$[6,6]$} & [4] \\
\hline & & $(372,425)$ & $(493,342)$ & $(372,378)$ & $(425,387)$ & $(493,464)$ & $(252)$ \\
\hline & \multirow{3}{*}{$\mathrm{PP}_{3,2}$} & $\{1\}$ & $\{3,4\}$ & $\{5\}$ & & & \\
\hline & & [7] & {$[8,8]$} & [9] & & & \\
\hline & & (575) & $(566,547)$ & $(567)$ & & & \\
\hline & \multirow{2}{*}{$\mathrm{PP}_{3,3}$} & $\{2,3\}$ & $\{4\}$ & $\{3,5\}$ & $\{4,6\}$ & $\{1,2\}$ & \\
\hline & & {$[7,6]$} & [7] & {$[7,8]$} & {$[7,8]$} & {$[1,4]$} & \\
\hline
\end{tabular}


Energy Efficient Network Manufacturing System using Controlled Elitist Non-dominated Sorting Genetic Algorithm

\begin{tabular}{|c|c|c|c|c|c|c|c|}
\hline & & $(521,425)$ & (479) & $(496,504)$ & $(479,619)$ & $(82,298)$ & \\
\hline \multirow{6}{*}{$\mathrm{J}_{4}$} & \multirow{3}{*}{$\mathrm{PP}_{4,1}$} & $\{1,2\}$ & $\{3,4\}$ & $\{6\}$ & $\{1\}$ & & \\
\hline & & {$[7,8]$} & {$[7,6]$} & [9] & [5] & & \\
\hline & & $(575,595)$ & $(496,410)$ & $(697)$ & (411) & & \\
\hline & \multirow{3}{*}{$\mathrm{PP}_{4,2}$} & $\{1,3,5\}$ & $\{2\}$ & $\{3,4,6\}$ & $\{5,6\}$ & & \\
\hline & & {$[4,3,7]$} & {$[4]$} & {$[4,5,6]$} & {$[3,5]$} & & \\
\hline & & $\begin{array}{c}(329,212 \\
441)\end{array}$ & (298) & $\begin{array}{c}(283,342, \\
464)\end{array}$ & $(189,387)$ & & \\
\hline \multirow{6}{*}{$\mathrm{J}_{5}$} & \multirow{3}{*}{$\mathrm{PP}_{5,1}$} & $\{1\}$ & $\{2,4\}$ & $\{3\}$ & $\{5,6\}$ & & \\
\hline & & [3] & {$[4,4]$} & [4] & {$[3,3]$} & & \\
\hline & & $(247)$ & $(298,274)$ & (283) & $(189,232)$ & & \\
\hline & \multirow{3}{*}{$\mathrm{PP}_{5,2}$} & $\{2,4\}$ & $\{5\}$ & $\{3,6\}$ & & & \\
\hline & & {$[5,6]$} & [7] & {$[9,8]$} & & & \\
\hline & & $(372,410)$ & (441) & $(437,619)$ & & & \\
\hline \multirow{9}{*}{ J6 } & \multirow{3}{*}{$\mathrm{PP}_{6,1}$} & $\{1,2\}$ & $\{3,4\}$ & $\{2,5\}$ & $\{3\}$ & $\{4,5\}$ & $\{3,6\}$ \\
\hline & & {$[3,4]$} & {$[4,3]$} & {$[5,3]$} & [4] & {$[5,6]$} & {$[5,4]$} \\
\hline & & $(247,298)$ & $(283,205)$ & $(372,189)$ & (283) & $\begin{array}{l}(343, \\
378) \\
\end{array}$ & $(354,310)$ \\
\hline & \multirow{3}{*}{$\mathrm{PP}_{6,2}$} & $\{1,3\}$ & $\{2,3\}$ & $\{2,4\}$ & $\{6\}$ & & \\
\hline & & {$[4,4]$} & {$[5,6]$} & {$[6,7]$} & [7] & & \\
\hline & & $(329,283)$ & $(372,425)$ & $(446,479)$ & (542) & & \\
\hline & \multirow{3}{*}{$\mathrm{PP}_{6,3}$} & $\{1,2,3\}$ & $\{4,5\}$ & $\{3,6\}$ & & & \\
\hline & & {$[3,5,8]$} & {$[7,10]$} & {$[9,9]$} & & & \\
\hline & & $\begin{array}{c}(247,372, \\
566)\end{array}$ & $(479,630)$ & $(637,697)$ & & & \\
\hline
\end{tabular}

Table 3. Input data of Scenario 2

\begin{tabular}{|c|c|c|c|c|c|c|}
\hline \multicolumn{7}{|c|}{ Input data of Scenario 2} \\
\hline & & & & Operations & & \\
\hline Job & PP & $\mathbf{O}_{1}$ & $\mathbf{O}_{2}$ & $\mathrm{O}_{3}$ & $\mathbf{O}_{4}$ & $\mathbf{O}_{5}$ \\
\hline \multirow{9}{*}{$\mathrm{J}_{1}$} & \multirow{3}{*}{$\mathrm{PP}_{1,1}$} & $\{2,4\}$ & $\{7,8\}$ & $\{1,2\}$ & $\{8,6\}$ & $\{3,8\}$ \\
\hline & & {$[18,22]$} & {$[39,36]$} & {$[11,10]$} & {$[31,34]$} & {$[26,24]$} \\
\hline & & $\begin{array}{l}(1339, \\
1505)\end{array}$ & $(3346,2138)$ & $(904,744)$ & $(1841,2632)$ & $(1841,1426)$ \\
\hline & \multirow{3}{*}{$\mathrm{PP}_{1,2}$} & $\{2,4\}$ & $\{3,5\}$ & $\{1,2,4\}$ & $\{5,6\}$ & $\{3,8\}$ \\
\hline & & {$[18,22]$} & {$[21,23]$} & {$[10,12,15]$} & {$[32,30]$} & {$[26,24]$} \\
\hline & & $\begin{array}{l}(1339, \\
1505)\end{array}$ & $(1487,1449)$ & $(822,893,1026)$ & $(2016,2322)$ & $(1841,1426)$ \\
\hline & \multirow{3}{*}{$\mathrm{PP}_{1,3}$} & $\{2,4\}$ & $\{3,5\}$ & $\{1,7\}$ & $\{3,8\}$ & \\
\hline & & {$[18,22]$} & {$[21,23]$} & {$[45,44]$} & {$[26,24]$} & \\
\hline & & $\begin{array}{l}(1339, \\
1505)\end{array}$ & $(1487,1449)$ & $(3699,3775)$ & $(1841,1426)$ & \\
\hline \multirow{12}{*}{$\mathrm{J}_{2}$} & \multirow{3}{*}{$\mathrm{PP}_{2,1}$} & $\{2,4\}$ & $\{7,8\}$ & $\{1,2\}$ & $\{3,8\}$ & \\
\hline & & {$[18,22]$} & {$[39,36]$} & {$[37,39]$} & {$[26,24]$} & \\
\hline & & $\begin{array}{l}(1339, \\
1505)\end{array}$ & $(3346,2138)$ & $(3041,2902)$ & $(1842,1426)$ & \\
\hline & \multirow{3}{*}{$\mathrm{PP}_{2,2}$} & $\{2,4\}$ & $\{8,6\}$ & $\{1,2,4\}$ & $\{5,6\}$ & $\{3,8\}$ \\
\hline & & {$[18,22]$} & {$[20,21]$} & {$[10,12,15]$} & {$[36,38]$} & {$[26,24]$} \\
\hline & & $\begin{array}{l}(1339, \\
1505)\end{array}$ & $(1188,1625)$ & $(822,893,1026)$ & $(2268,2941)$ & $(1841,1426)$ \\
\hline & \multirow{3}{*}{$\mathrm{PP}_{2,3}$} & $\{2,4\}$ & $\{8,6\}$ & $\{1,7\}$ & $\{3,8\}$ & \\
\hline & & {$[18,22]$} & {$[20,21]$} & {$[45,44]$} & {$[26,24]$} & \\
\hline & & $\begin{array}{l}(1339, \\
1505)\end{array}$ & $(1188,1625)$ & $(3699,3775)$ & $(1842,1426)$ & \\
\hline & \multirow{3}{*}{$\mathrm{PP}_{2,4}$} & $\{2,4\}$ & $\{3,5\}$ & $\{1,2,4\}$ & $\{5,6\}$ & $\{3,8\}$ \\
\hline & & {$[18,22]$} & {$[21,23]$} & {$[10,12,15]$} & {$[36,38]$} & {$[26,24]$} \\
\hline & & $(1339$, & $(1487,1449)$ & $(822,893,1026)$ & $(2268,2941)$ & $(1841,1426)$ \\
\hline
\end{tabular}




\begin{tabular}{|c|c|c|c|c|c|c|}
\hline & & 1505) & & & & \\
\hline & \multirow{3}{*}{$\mathrm{PP}_{2,5}$} & $\{2,4\}$ & $\{3,5\}$ & $\{1,7\}$ & $\{3,8\}$ & \\
\hline & & {$[18,22]$} & {$[21,23]$} & {$[45,44]$} & {$[26,24]$} & \\
\hline & & $\begin{array}{l}(1339, \\
1505)\end{array}$ & $(1487,1449)$ & $(3699,3775)$ & $(1842,1426)$ & \\
\hline \multirow{9}{*}{$\mathrm{J}_{3}$} & \multirow{3}{*}{$\mathrm{PP}_{3,1}$} & $\{1,4\}$ & $\{6,7\}$ & $\{5,8\}$ & $\{2,4\}$ & \\
\hline & & {$[22,25]$} & {$[24,22]$} & {$[20,19]$} & {$[22,27]$} & \\
\hline & & $\begin{array}{l}(1808, \\
1710)\end{array}$ & $(1858,1888)$ & $(1260,1129)$ & $(1637,1847)$ & \\
\hline & \multirow{3}{*}{$\mathrm{PP}_{3,2}$} & $\{3,5\}$ & $\{4,6\}$ & $\{2,3,5\}$ & $\{2,4\}$ & \\
\hline & & {$[12,15]$} & {$[24,23]$} & {$[30,31,24]$} & {$[22,27]$} & \\
\hline & & $(850,945)$ & $(1642,1780)$ & $(2232,2195,1512)$ & $(1637,1847)$ & \\
\hline & \multirow{3}{*}{$\mathrm{PP}_{3,3}$} & $\{3,5\}$ & $\{6,7\}$ & $\{1,8\}$ & $\{2,4\}$ & \\
\hline & & {$[12,15]$} & {$[21,22]$} & {$[32,30]$} & {$[22,27]$} & \\
\hline & & $(850,945)$ & $(1625,1888)$ & $(2630,1782)$ & $(1637,1847)$ & \\
\hline \multirow{12}{*}{$\mathrm{J}_{4}$} & \multirow{3}{*}{$\mathrm{PP}_{4,1}$} & $\{1,4\}$ & $\{6,7\}$ & $\{2,4\}$ & & \\
\hline & & {$[22,25]$} & {$[42,44]$} & {$[22,27]$} & & \\
\hline & & $\begin{array}{l}(1808, \\
1710)\end{array}$ & $(3251,3775)$ & $(1637,1847)$ & & \\
\hline & \multirow{3}{*}{$\mathrm{PP}_{4,2}$} & $\{1,4\}$ & $\{5,8\}$ & $\{2,4\}$ & & \\
\hline & & {$[22,25]$} & {$[41,43]$} & {$[22,27]$} & & \\
\hline & & $\begin{array}{l}(1808, \\
1710)\end{array}$ & $(2583,2554)$ & $(1637,1847)$ & & \\
\hline & \multirow{3}{*}{$\mathrm{PP}_{4,3}$} & $\{3,5\}$ & $\{4,5\}$ & $\{2,3,5\}$ & $\{2,4\}$ & \\
\hline & & {$[12,15]$} & {$[24,23]$} & {$[30,31,29]$} & {$[22,27]$} & \\
\hline & & $(850,945)$ & $(1642,1449)$ & $(2232,2195,1827)$ & $(1637,1847)$ & \\
\hline & \multirow{3}{*}{$\mathrm{PP}_{4,4}$} & $\{3,5\}$ & $\{6,7\}$ & $\{1,8\}$ & $\{2,4\}$ & \\
\hline & & {$[12,15]$} & {$[21,22]$} & {$[32,30]$} & {$[22,27]$} & \\
\hline & & $(850,945)$ & $(1625,1888)$ & $(2630,1782)$ & $(1637,1847)$ & \\
\hline \multirow{9}{*}{$\mathrm{J}_{5}$} & \multirow{3}{*}{$\mathrm{PP}_{5,1}$} & $\{2,4\}$ & $\{1,3\}$ & $\{6,7\}$ & $\{5,8\}$ & $\{3,4\}$ \\
\hline & & {$[18,22]$} & {$[22,25]$} & {$[24,22]$} & {$[20,18]$} & {$[22,27]$} \\
\hline & & $\begin{array}{l}(1339, \\
1505)\end{array}$ & $(1808,1770)$ & $(1858,1888)$ & $(1260,1069)$ & $(1558,1847)$ \\
\hline & \multirow{3}{*}{$\mathrm{PP}_{5,2}$} & $\{2,4\}$ & $\{3,5\}$ & $\{6,8\}$ & $\{1,7\}$ & $\{3,4\}$ \\
\hline & & {$[18,22]$} & {$[12,15]$} & {$[19,21]$} & {$[32,31]$} & {$[22,27]$} \\
\hline & & $\begin{array}{l}(1339, \\
1505)\end{array}$ & $(850,945)$ & $(1471,1247)$ & $(2630,2660)$ & $(1558,1847)$ \\
\hline & \multirow{3}{*}{$\mathrm{PP}_{5,3}$} & $\{2,4\}$ & $\{3,5\}$ & $\{1,2,6\}$ & $\{3,4\}$ & \\
\hline & & {$[18,22]$} & {$[12,15]$} & {$[50,52,54]$} & {$[22,27]$} & \\
\hline & & $\begin{array}{l}(1339, \\
1505)\end{array}$ & $(850,945)$ & $(4110,3869,4180)$ & $(1558,1847)$ & \\
\hline \multirow{12}{*}{ J6 } & \multirow{3}{*}{$\mathrm{PP}_{6,1}$} & $\{2,4\}$ & $\{1,7\}$ & $\{6,7\}$ & $\{5,8\}$ & $\{3,4\}$ \\
\hline & & {$[18,22]$} & {$[22,24]$} & {$[24,22]$} & {$[20,18]$} & {$[22,27]$} \\
\hline & & $\begin{array}{l}(1339, \\
1505)\end{array}$ & $(1808,2059)$ & $(1858,1888)$ & $(1260,1069)$ & $(1558,1847)$ \\
\hline & \multirow{3}{*}{$\mathrm{PP}_{6,2}$} & $\{2,4\}$ & $\{1,3\}$ & $\{6,7\}$ & $\{5,8\}$ & $\{3,4\}$ \\
\hline & & {$[18,22]$} & {$[21,25]$} & {$[24,22]$} & {$[20,18]$} & {$[22,27]$} \\
\hline & & $\begin{array}{l}(1339, \\
1505)\end{array}$ & $(1726,1770)$ & $(1858,1888)$ & $(1260,1069)$ & $(1558,1847)$ \\
\hline & \multirow{3}{*}{$\mathrm{PP}_{6,3}$} & $\{2,4\}$ & $\{3,5\}$ & $\{6,8\}$ & $\{3,4\}$ & \\
\hline & & {$[18,22]$} & {$[12,15]$} & {$[53,51]$} & {$[22,27]$} & \\
\hline & & $\begin{array}{l}(1339, \\
1505)\end{array}$ & $(850,945)$ & $(4102,3029)$ & $(1558,1847)$ & \\
\hline & \multirow{3}{*}{$\mathrm{PP}_{6,4}$} & $\{2,4\}$ & $\{3,5\}$ & $\{1,2,6\}$ & $\{3,4\}$ & \\
\hline & & {$[18,22]$} & {$[12,15]$} & {$[50,52,54]$} & {$[22,27]$} & \\
\hline & & $\begin{array}{l}(1339, \\
1505)\end{array}$ & $(850,945)$ & $(4110,3869,4180)$ & $(1558,1847)$ & \\
\hline
\end{tabular}


Table 4. Input data of Scenario 3

\begin{tabular}{|c|c|c|c|c|c|c|}
\hline \multicolumn{7}{|c|}{ Input data of Scenario 3} \\
\hline & & & & Operations & & \\
\hline Job & PP & $\mathbf{O}_{1}$ & $\mathbf{O}_{2}$ & $\mathrm{O}_{3}$ & $\mathbf{O}_{4}$ & $\mathbf{O}_{5}$ \\
\hline \multirow{9}{*}{$\mathrm{J}_{1}$} & \multirow{3}{*}{$\mathrm{PP}_{1,1}$} & $\{2,4\}$ & $\{7,8\}$ & $\{1,2\}$ & $\{8,6\}$ & $\{3,8\}$ \\
\hline & & {$[18,22]$} & {$[39,36]$} & {$[11,10]$} & {$[31,34]$} & {$[26,24]$} \\
\hline & & $(1339,1505)$ & $(3346,2138)$ & $(904,744)$ & $(1841,2632)$ & $(1841,1426)$ \\
\hline & \multirow{3}{*}{$\mathrm{PP}_{1,2}$} & $\{2,4\}$ & $\{3,5\}$ & $\{1,2,4\}$ & $\{5,6\}$ & $\{3,8\}$ \\
\hline & & {$[18,22]$} & {$[21,23]$} & {$[10,12,15]$} & {$[32,30]$} & {$[26,24]$} \\
\hline & & $(1339,1505)$ & $(1487,1449)$ & $(822,893,1026)$ & $(2016,2322)$ & $(1841,1426)$ \\
\hline & \multirow{3}{*}{$\mathrm{PP}_{1,3}$} & $\{2,4\}$ & $\{3,5\}$ & $\{1,7\}$ & $\{3,8\}$ & \\
\hline & & {$[18,22]$} & {$[21,23]$} & {$[45,44]$} & {$[26,24]$} & \\
\hline & & $(1339,1505)$ & $(1487,1449)$ & $(3699,3775)$ & $(1841,1426)$ & \\
\hline \multirow{15}{*}{$\mathrm{J}_{2}$} & \multirow{3}{*}{$\mathrm{PP}_{2,1}$} & $\{2,4\}$ & $\{7,8\}$ & $\{1,2\}$ & $\{3,8\}$ & \\
\hline & & {$[18,22]$} & {$[39,36]$} & {$[37,39]$} & {$[26,24]$} & \\
\hline & & $(1339,1505)$ & $(3346,2138)$ & $(3041,2902)$ & $(1842,1426)$ & \\
\hline & \multirow{3}{*}{$\mathrm{PP}_{2,2}$} & $\{2,4\}$ & $\{8,6\}$ & $\{1,2,4\}$ & $\{5,6\}$ & $\{3,8\}$ \\
\hline & & {$[18,22]$} & {$[20,21]$} & {$[10,12,15]$} & {$[36,38]$} & {$[26,24]$} \\
\hline & & $(1339,1505)$ & $(1188,1625)$ & $(822,893,1026)$ & $(2268,2941)$ & $(1841,1426)$ \\
\hline & \multirow{3}{*}{$\mathrm{PP}_{2,3}$} & $\{2,4\}$ & $\{8,6\}$ & $\{1,7\}$ & $\{3,8\}$ & \\
\hline & & {$[18,22]$} & {$[20,21]$} & {$[45,44]$} & {$[26,24]$} & \\
\hline & & $(1339,1505)$ & $(1188,1625)$ & $(3699,3775)$ & $(1842,1426)$ & \\
\hline & \multirow{3}{*}{$\mathrm{PP}_{2,4}$} & $\{2,4\}$ & $\{3,5\}$ & $\{1,2,4\}$ & $\{5,6\}$ & $\{3,8\}$ \\
\hline & & {$[18,22]$} & {$[21,23]$} & {$[10,12,15]$} & {$[36,38]$} & {$[26,24]$} \\
\hline & & $(1339,1505)$ & $(1487,1449)$ & $(822,893,1026)$ & $(2268,2941)$ & $(1841,1426)$ \\
\hline & \multirow{3}{*}{$\mathrm{PP}_{2,5}$} & $\{2,4\}$ & $\{3,5\}$ & $\{1,7\}$ & $\{3,8\}$ & \\
\hline & & {$[18,22]$} & {$[21,23]$} & {$[45,44]$} & {$[26,24]$} & \\
\hline & & $(1339,1505)$ & $(1487,1449)$ & $(3699,3775)$ & $(1842,1426)$ & \\
\hline \multirow{9}{*}{$\mathrm{J}_{3}$} & \multirow{3}{*}{$\mathrm{PP}_{3,1}$} & $\{1,4\}$ & $\{6,7\}$ & $\{5,8\}$ & $\{2,4\}$ & \\
\hline & & {$[22,25]$} & {$[24,22]$} & {$[20,19]$} & {$[22,27]$} & \\
\hline & & $(1808,1710)$ & $(1858,1888)$ & $(1260,1129)$ & $(1637,1847)$ & \\
\hline & \multirow{3}{*}{$\mathrm{PP}_{3,2}$} & $\{3,5\}$ & $\{4,6\}$ & $\{2,3,5\}$ & $\{2,4\}$ & \\
\hline & & {$[12,15]$} & {$[24,23]$} & {$[30,31,24]$} & {$[22,27]$} & \\
\hline & & $(850,945)$ & $(1642,1780)$ & $\begin{array}{c}(2232,2195 \\
1512) \\
\end{array}$ & $(1637,1847)$ & \\
\hline & \multirow{3}{*}{$\mathrm{PP}_{3,3}$} & $\{3,5\}$ & $\{6,7\}$ & $\{1,8\}$ & $\{2,4\}$ & \\
\hline & & {$[12,15]$} & {$[21,22]$} & {$[32,30]$} & {$[22,27]$} & \\
\hline & & $(850,945)$ & $(1625,1888)$ & $(2630,1782)$ & $(1637,1847)$ & \\
\hline \multirow{12}{*}{$\mathrm{J}_{4}$} & \multirow{3}{*}{$\mathrm{PP}_{4,1}$} & $\{1,4\}$ & $\{6,7\}$ & $\{2,4\}$ & & \\
\hline & & {$[22,25]$} & {$[42,44]$} & {$[22,27]$} & & \\
\hline & & $(1808,1710)$ & $(3251,3775)$ & $(1637,1847)$ & & \\
\hline & \multirow{3}{*}{$\mathrm{PP}_{4,2}$} & $\{1,4\}$ & $\{5,8\}$ & $\{2,4\}$ & & \\
\hline & & {$[22,25]$} & {$[41,43]$} & {$[22,27]$} & & \\
\hline & & $(1808,1710)$ & $(2583,2554)$ & $(1637,1847)$ & & \\
\hline & \multirow{3}{*}{$\mathrm{PP}_{4,3}$} & $\{3,5\}$ & $\{4,5\}$ & $\{2,3,5\}$ & $\{2,4\}$ & \\
\hline & & {$[12,15]$} & {$[24,23]$} & {$[30,31,29]$} & {$[22,27]$} & \\
\hline & & $(850,945)$ & $(1642,1449)$ & $\begin{array}{c}(2232,2195 \\
1827)\end{array}$ & $(1637,1847)$ & \\
\hline & & $\{3,5\}$ & $\{6,7\}$ & $\{1,8\}$ & $\{2,4\}$ & \\
\hline & $\mathrm{PP}_{4,4}$ & {$[12,15]$} & {$[21,22]$} & {$[32,30]$} & {$[22,27]$} & \\
\hline & & $(850,945)$ & $(1625,1888)$ & $(2630,1782)$ & $(1637,1847)$ & \\
\hline & & $\{2,4\}$ & $\{1,3\}$ & $\{6,7\}$ & $\{5,8\}$ & $\{3,4\}$ \\
\hline & $\mathrm{PP}_{5,1}$ & {$[18,22]$} & {$[22,25]$} & {$[24,22]$} & {$[20,18]$} & {$[22,27]$} \\
\hline$J_{5}$ & & $(1339,1505)$ & $(1808,1770)$ & $(1858,1888)$ & $(1260,1069)$ & $(1558,1847)$ \\
\hline 15 & & $\{2,4\}$ & $\{3,5\}$ & $\{6,8\}$ & $\{1,7\}$ & $\{3,4\}$ \\
\hline & $\mathrm{PP}_{5,2}$ & {$[18,22]$} & {$[12,15]$} & {$[19,21]$} & {$[32,31]$} & {$[22,27]$} \\
\hline & & $(1339,1505)$ & $(850,945)$ & $(1471,1247)$ & $(2630,2660)$ & $(1558,1847)$ \\
\hline
\end{tabular}




\begin{tabular}{|c|c|c|c|c|c|c|}
\hline & \multirow{3}{*}{$\mathrm{PP}_{5,3}$} & $\{2,4\}$ & $\{3,5\}$ & $\{1,2,6\}$ & $\{3,4\}$ & \\
\hline & & {$[18,22]$} & {$[12,15]$} & {$[50,52,54]$} & {$[22,27]$} & \\
\hline & & $(1339,1505)$ & $(850,945)$ & $\begin{array}{c}(4110,3869, \\
4180)\end{array}$ & $(1558,1847)$ & \\
\hline \multirow{12}{*}{$\mathrm{J}_{6}$} & \multirow{3}{*}{$\mathrm{PP}_{6,1}$} & $\{2,4\}$ & $\{1,7\}$ & $\{6,7\}$ & $\{5,8\}$ & $\{3,4\}$ \\
\hline & & {$[18,22]$} & {$[22,24]$} & {$[24,22]$} & {$[20,18]$} & {$[22,27]$} \\
\hline & & $(1339,1505)$ & $(1808,2059)$ & $(1858,1888)$ & $(1260,1069)$ & $(1558,1847)$ \\
\hline & \multirow{3}{*}{$\mathrm{PP}_{6,2}$} & $\{2,4\}$ & $\{1,3\}$ & $\{6,7\}$ & $\{5,8\}$ & $\{3,4\}$ \\
\hline & & {$[18,22]$} & {$[21,25]$} & {$[24,22]$} & {$[20,18]$} & {$[22,27]$} \\
\hline & & $(1339,1505)$ & $(1726,1770)$ & $(1858,1888)$ & $(1260,1069)$ & $(1558,1847)$ \\
\hline & \multirow{3}{*}{$\mathrm{PP}_{6,3}$} & $\{2,4\}$ & $\{3,5\}$ & $\{6,8\}$ & $\{3,4\}$ & \\
\hline & & {$[18,22]$} & {$[12,15]$} & {$[53,51]$} & {$[22,27]$} & \\
\hline & & $(1339,1505)$ & $(850,945)$ & $(4102,3029)$ & $(1558,1847)$ & \\
\hline & \multirow{3}{*}{$P_{6,4}$} & $\{2,4\}$ & $\{3,5\}$ & $\{1,2,6\}$ & $\{3,4\}$ & \\
\hline & & {$[18,22]$} & {$[12,15]$} & {$[50,52,54]$} & {$[22,27]$} & \\
\hline & & $(1339,1505)$ & $(850,945)$ & $\begin{array}{c}(4110,3869, \\
4180)\end{array}$ & $(1558,1847)$ & \\
\hline
\end{tabular}

Table 5. Job scheduling of Case 1

\begin{tabular}{|c|c|c|c|}
\hline $\begin{array}{c}\text { Job } \\
\text { No }\end{array}$ & $\begin{array}{c}\text { Makespan } \\
\text { (Min) }\end{array}$ & $\begin{array}{c}\text { Process } \\
\text { plan }\end{array}$ & $\begin{array}{c}\text { Scheduling of } \\
\text { jobs }\end{array}$ \\
\hline 1 & 20 & 2 & {$[3,2,5,5]$} \\
\hline 2 & 18 & 2 & {$[1,4,4,4,4,6]$} \\
\hline 3 & 24 & 2 & {$[1,4,5]$} \\
\hline 4 & 22 & 2 & {$[5,2,6,6]$} \\
\hline 5 & 20 & 2 & {$[2,5,6]$} \\
\hline 6 & 24 & 2 & {$[3,3,4,6]$} \\
\hline
\end{tabular}

Table 6. Job scheduling of Case 2

\begin{tabular}{|c|c|c|c|}
\hline $\begin{array}{c}\text { Job } \\
\text { No }\end{array}$ & $\begin{array}{c}\text { Makespan } \\
\text { (Min) }\end{array}$ & $\begin{array}{c}\text { Process } \\
\text { plan }\end{array}$ & $\begin{array}{c}\text { Scheduling of } \\
\text { jobs }\end{array}$ \\
\hline 1 & 22 & 2 & {$[1,2,3,8]$} \\
\hline 2 & 24 & 2 & {$[3,4,4,4,4,8,4]$} \\
\hline 3 & 23 & 2 & {$[1,3,8]$} \\
\hline 4 & 19 & 2 & {$[1,2,6,6]$} \\
\hline 5 & 14 & 1 & {$[1,2,3,8]$} \\
\hline 6 & 22 & 2 & {$[3,3,7,6]$} \\
\hline 7 & 23 & 1 & {$[2,4,6,5,6]$} \\
\hline 8 & 18 & 2 & {$[2,4,6]$} \\
\hline
\end{tabular}

Table 7. Job scheduling of Case 3

\begin{tabular}{|c|c|c|c|}
\hline & \multicolumn{3}{|c|}{ Case 3 } \\
\hline Job No & $\begin{array}{c}\text { Makespan } \\
\text { (Min) }\end{array}$ & $\begin{array}{c}\text { Process } \\
\text { plan }\end{array}$ & $\begin{array}{c}\text { Scheduling of } \\
\text { jobs }\end{array}$ \\
\hline 1 & 107 & 3 & {$[2,3,7,8]$} \\
\hline 2 & 109 & 5 & {$[2,3,7,3]$} \\
\hline 3 & 105 & 2 & {$[5,6,2,4]$} \\
\hline 4 & 94 & 3 & {$[3,4,3,4]$} \\
\hline 5 & 116 & 3 & {$[4,3,6,4]$} \\
\hline 6 & 105 & 4 & {$[2,5,1,3]$} \\
\hline
\end{tabular}



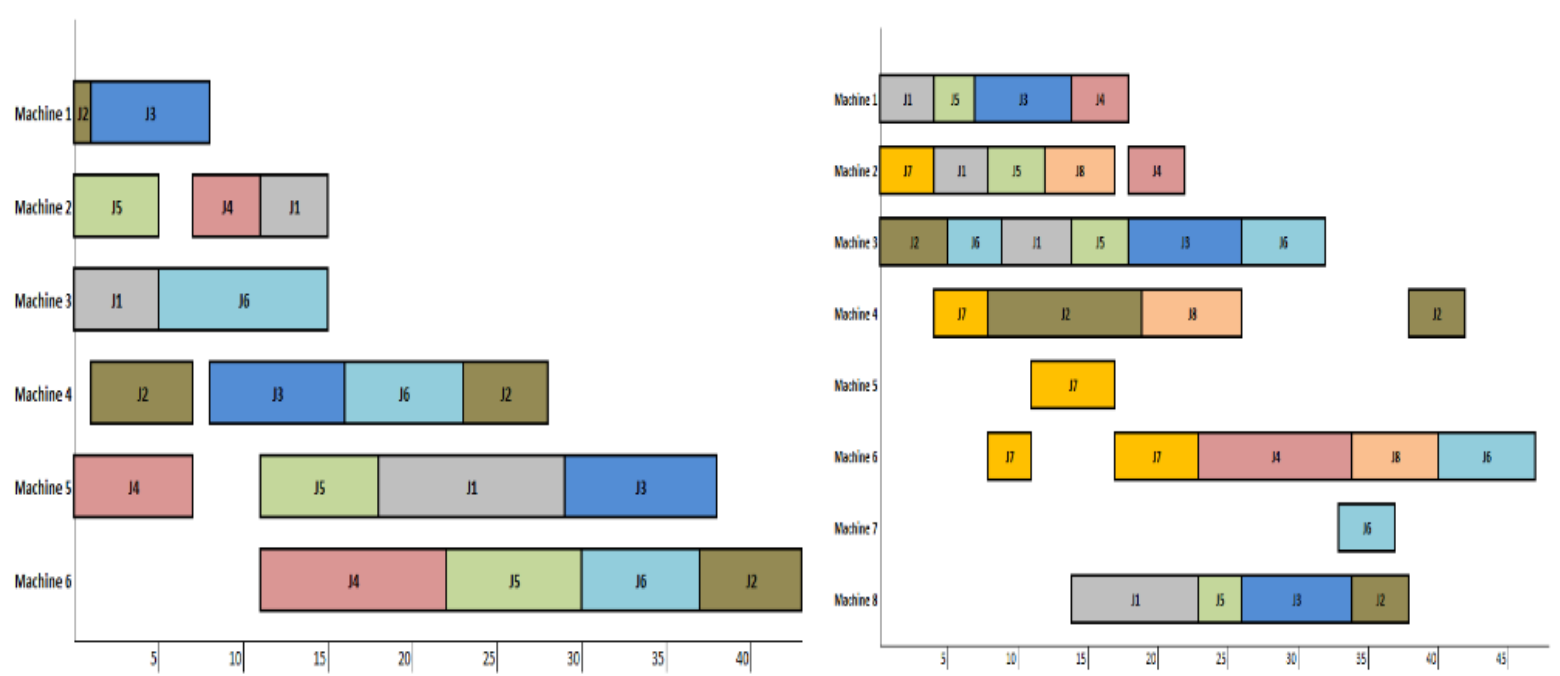

Figure 2 and Figure 3 Gantt chart showing job scheduling for Scenario 1 and 2

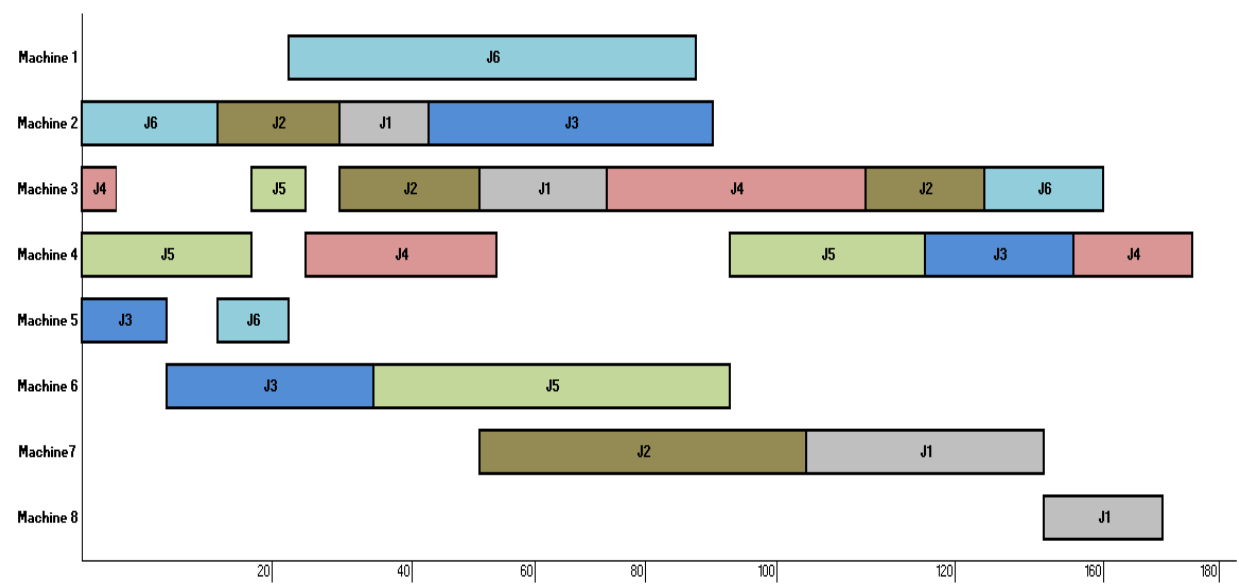

Figure 4. Gantt chart showing job scheduling for Scenario 3

\section{Results and Discussion}

The parameters deciding the performance of the projected algorithm are the utilization of machines, makespan, number of generations, and computational run time. Three incompatible objectives are selected in our paper as minimization of makespan, minimization of energy consumption, and maximization of machine utilization. Better efficiency of the algorithm and higher productivity of the manufacturing system can be assured with lesser makespan value.

In Tables 4, 5 and 6, the total makespan i.e., the total of processing times on each machine for each job; the optimal process plan that is selected from the set of alternatives provided and the scheduling of jobs as to "on which machine which operation is performed" has been provided. The makespan, energy consumption, machine utilization, and computational time for fittest solutions are detailed in Table 7.

Table 8. Overall optimized value of objective functions

\begin{tabular}{|c|c|c|c|c|}
\hline Experiment & $\begin{array}{c}\text { Makespan } \\
\text { (Min) }\end{array}$ & $\begin{array}{c}\text { Energy } \\
\text { Consumption } \\
\text { (KJ) }\end{array}$ & $\begin{array}{c}\text { Machine } \\
\text { Utilization (\%) }\end{array}$ & $\begin{array}{c}\text { Execution Time } \\
\text { (Sec) }\end{array}$ \\
\hline Scenario 1 & 43 & 9083 & 94.82 & 4.2377 \\
\hline Scenario 2 & 47 & 11889 & 90.16 & 5.6243 \\
\hline Scenario 3 & 173 & 46142 & 91.12 & 5.1098 \\
\hline
\end{tabular}


It can be referred that the proposed algorithm converges fast because it encounters termination norms in a lower number of generations. Though, obtaining lower computational time with fewer generations is not guaranteed because each algorithm has particular intricacy implicated for every single run of programming. This occurrence leads to the concern of computational time and the proposed algorithm deals with several generations and computational time in an equivalent manner and provides justified computational time so that reaction of manufacturing resources is improved through quick process plan generation. Energy efficiency and cost-effectiveness of any manufacturing sector can be improved with lower energy consumption through proper process plan and scheduling selection which can be inferred from our results. One more crucial factor is the superior consumption of manufacturing resources which is termed as "Machine Utilization" and can be defined as the percentage ratio of real operation processing time to the overall running time of all the machines.
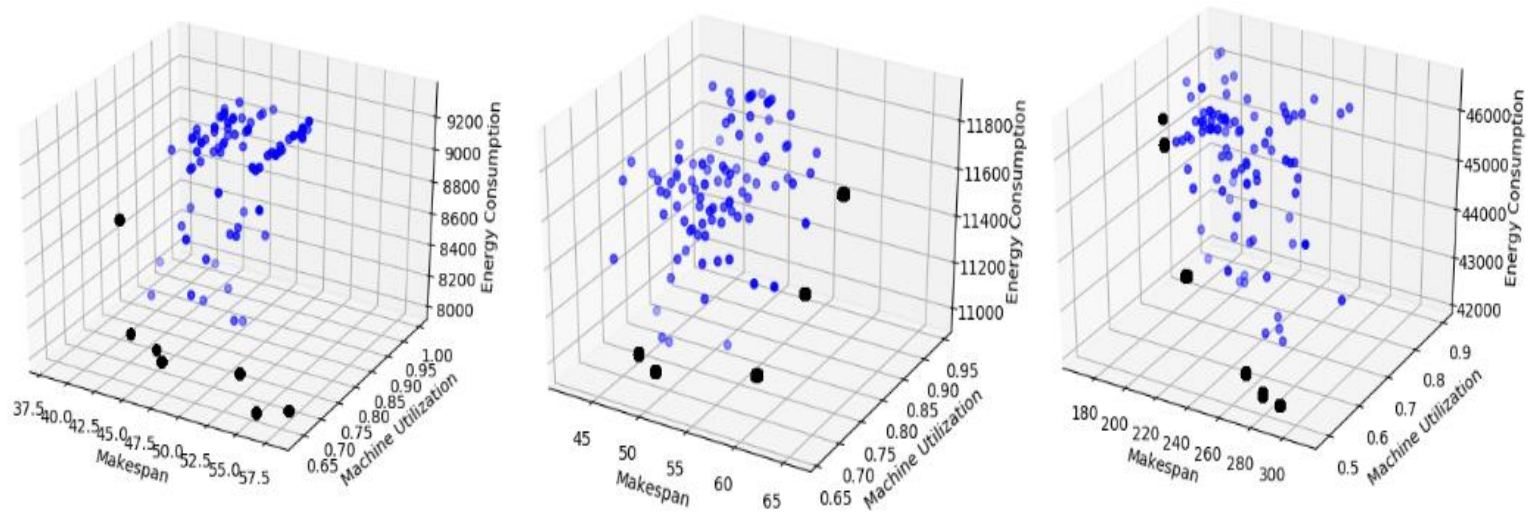

Figure 5. Pareto fronts for Scenario 1, 2 and 3

The scatter plots of the optimal Pareto-fronts for the three cases have been shown in Fig. 5. The dark highlighted points show the locus of the optimal Pareto-fronts obtained. A Pareto-front contains all reasonable solutions based on the objective functions and constraints.

Although there are various methods to choose the best solution; one of the simplest and easiest ways is to compare with the ideal point and recognize the point closest to the ideal point. Also, the solution chosen from the frontiers depends on the perspective of the decision-maker. This CENSGA-II algorithm has been coded in Python 3 and tested on Intel ${ }^{\circledR}$ Core $^{\mathrm{TM}}$ i5-4200U CPU @1.6GHz $2.30 \mathrm{GHz}, 4 \mathrm{~GB}$ of RAM. In the end, it can be realized from the results that CE- NSGA-II executes efficiently with a lower number of generations to obtain optimized objective functions with improved convergence and divergence of solutions.

\section{Conclusion}

In this research study, investigation of variation between traditional and network manufacturing systems helped us to identify the importance and necessity of networked manufacturing system and their characteristics. Consequently, problem description with the mathematical model is formulated with certain assumptions, constraints, and makespan minimization, machine utilization maximization, and minimization of energy consumption are taken as objectives with the IPPS approach.

Practical machine parameters are characterized like speed, power, etc. and the energy consumption is computed through a mathematical model for each operation-machine combination. The problem being a type of NP-hard complex problem, the CE-NSGA-II algorithm is proposed to fulfill the objective needs and produce a feasible process plan. Further on need, more sub-objectives are introduced like several generations, each job's optimal process plan and computational time which categorize the performance of the proposed algorithm substantially.

\section{References}

[1] Haapala, K.R., Zhao, F., Camelio, J., Sutherland, J.W., Skerlos, S.J., Dornfeld, D.A., Jawahir, I.S., Clarens, A.F. and Rickli, J.L., 2013. A review of engineering research in sustainable manufacturing. Journal of Manufacturing Science and Engineering, 135(4).

[2] Jovane, F., Yoshikawa, H., Alting, L., Boer, C.R., Westkamper, E., Williams, D., Tseng, M., Seliger, G. and Paci, A.M., 2008. The incoming global technological and industrial revolution towards competitive sustainable manufacturing. CIRP annals, 57(2), pp.641-659. 
[3] Peklenik, J. and Jerele, A., 1992. Some basic relationships for identification of the machining processes. CIRP annals, 41(1), pp.155-159.

[4] Veeramani, D. and Wang, K.J., 1997. Performance analysis of auction-based distributed shop-floor control schemes from the perspective of the communication system. International journal of flexible manufacturing systems, 9(2), pp.121-143.

[5] De Wilde, P. and Briscoe, G., 2011. Stability of evolving multiagent systems. IEEE Transactions on Systems, Man, and Cybernetics, Part B (Cybernetics), 41(4), pp.1149-1157.

[6] Varela, M.L., Putnik, G.D., Manupati, V.K., Rajyalakshmi, G., Trojanowska, J. and Machado, J., 2018. Collaborative manufacturing based on cloud, and on other i4. 0 oriented principles and technologies: a systematic literature review and reflections. Management and Production Engineering Review, 9.
[7] Ausaf, M.F., Gao, L., Li, X. and Al Aqel, G., 2015. A priority-based heuristic algorithm (PBHA) for optimizing integrated process planning and scheduling problem.Cogent Engineering,2(1), p.1070494.

[8] Lin, J., Liu, M., Hao, J. and Jiang, S., 2016. A multiobjective optimization approach for integrated production planning under interval uncertainties in the steel industry. Computers \& Operations Research, 72, pp.189-203.

[9] Luo, G., Wen, X., Li, H., Ming, W. and Xie, G., 2017. An effective multi-objective genetic algorithm based on immune principle and external archive for multi-objective integrated process planning and scheduling. The International Journal of Advanced Manufacturing Technology,91(9-12), pp.3145-3158.

[10] Zhao, B., Gao, J., Chen, K. and Guo, K., 2018. Two-generation Pareto ant colony algorithm for multi-objective job shop scheduling problem with alternative process plans and unrelated parallel machines.Journal of Intelligent Manufacturing, 29(1), pp.93-108. 